\title{
Lipoid Proteinosis of Urbach and Wiethe
}

National Cancer Institute

\section{Source}

National Cancer Institute. Lipoid Proteinosis of Urbach and Wiethe. NCI Thesaurus. Code C84829.

A rare, autosomal recessive metabolic disorder characterized by hoarseness of voice, eyelid beading, skin lesions, and seizures. 